\title{
LA CIVITAS MEDIEVALIS EN EL PENSAMIENTO DE MACHIAVELLI
}

Bruno Gelati*

\section{Premisa: El poder}

\begin{abstract}
L a edad moderna -afirma Romano Guardini- había acogido como victoria absoluta todo aumento de la potencia científica y técnica; sus propias conquistas le habían parecido un progreso hacia realizaciones más decisivas y hacia una riqueza de valores más elevadas de la existencia.

Pero -continúa el filósofo italo-alemán- la certeza de esta convicción viene sacudida: es aquí que se revela el inicio de la época nueva. Ya no se piensa que un aumento de poder sea sinónimo de elevación de los valores de la vida. El poder nos aparece problemático en su esencia.

En la conciencia común se hace camino el sentimiento de que nuestra relación con el poder está equivocada; además, en la medida en la que este poder aumenta, es una amenaza para nosotros. $^{1}$
\end{abstract}

Guardini todavía precisa que "el poder es un fenómeno específicamente humano" ${ }^{2}$ y en sí no negativo. En efecto, no se habla del poder animal o de una naturaleza que no sea personal.

* Departamento Académico de Estudios Generales, ITAM.

${ }^{1}$ Cfr. R. Guardini, La fine de la época moderna, Il potere, 1993, Brescia, Morcelliana, p. 114. La traducción es mía.

${ }^{2}$ Ibid., p. 119. 
Estas afirmaciones nos inducen, de entrada, a formular la hipótesis de que el concepto de poder en Machiavelli no se identifica todavía con el que Guardini denuncia ser el mal oscuro del rostro del poder en la época moderna; intuición inicial, ésta, que nos empeña en una búsqueda más profunda del pensamiento de quien está considerado como el iniciador de la política moderna y que sin embargo que no se puede identificar tout-court con los males de la modernidad.

En fin, podemos atrevernos a decir que nuestro autor no puede ser definido dentro de los parámetros que el filósofo italo-alemán presenta como las contradicciones también de nuestra época. En particular, cuando afirma que:

Una mirada del conjunto nos da la impresión de que sea la naturaleza, sea el hombre mismo estén siempre más a la merced de la imperiosa pretensión del poder económico, técnico, organizativo, estatal. Siempre más claramente se delinea una situación en la cual el hombre tiene en su poder la naturaleza, pero conjuntamente el hombre tiene en su poder al hombre y el Estado tiene en su poder al pueblo y el círculo vicioso del sistema técnico-económico tiene en su poder la vida. ${ }^{3}$

Parece entonces que se pudiera intuir cierta distancia entre la cara con la que se presenta en nuestra época el poder y la intención con la que Machiavelli escribe El príncipe; sin embargo, estamos todavía en el inicio de nuestra hipótesis reflexiva.

Quizá nos ayude pensar, siempre siguiendo a Guardini, qué es finalmente el poder.

En sentido propio, podemos entonces hablar de poder sólo cuando se dan dos elementos; por un lado, una verdadera energía, en grado de modificar a la realidad de las cosas y de determinar sus condiciones y sus relaciones recíprocas; por

${ }^{3}$ Ibid., p. 160. 
otra parte, una conciencia que se dé cuenta [de lo que hace]; una voluntad que establezca metas; una capacidad que disponga de la fuerza para lograr aquellas metas. ${ }^{4}$

Si bien, todavía siempre intuitivamente, pero con más proximidad por acierto, podemos también detectar una diferencia igualmente razonable entre el concepto de poder que se irá afirmando más y más en la época moderna y contemporánea, con respecto de sus imprecisos inicios.

Sería superficial y hasta ideológico aunar someramente procesos que, incluso, podrían marcar surcos sugerentes para una revisión cultural de la historia política moderna, es decir para una clave interpretativa más amplia y más unitaria de su pensamiento; en particular, menos homologada como es el caso del pluralismo del pensamiento político en los albores de la época moderna, el que ha enriquecido, en sus múltiples facetas, un mismo período histórico y cultural. La continuidad cultural, en efecto, no está en desacuerdo con la diversidad.

Estos aspectos se pueden entrever con claridad en la obra de Machiavelli: su pensamiento -en El príncipe, en particular- brilla desde el inicio por su audaz originalidad.

Precisamente, uno de los equívocos en los cuales se ha incurrido, tal vez por ciertos esquemas mentales, tiene que ver con la idea de poder: sería distorsionar al Florentino trasladar, sin previas consideraciones a la realidad actual, su genialidad política; sobre todo cuando en un cierto sentido es casi obligación pasar por el filtro homologador de la Ilustración, sin considerar, en cambio, la novedad que han constituido sus tratados políticos; novedad que sólo puede ser percibida en relación más bien con el sentido de un continuum con la época tan heterogénea y heterodoxa anterior a él y que inquietantemente le ha involucrado en sus búsquedas, lo que ha permitido incluso dar al poder un rostro seguramente más realista.

${ }^{4}$ Ibid., p. 118. 
BRUNO GELATI

Dicho sea de paso, para los pensadores todavía del humanismo, lo novedoso consistía en intentar algo que no había sido dicho con anterioridad; pero no con el afán de lo que hoy día entendemos por la palabra novedad, sinónimo de curiosidad superficial, sino que se trataba más bien de no repetir ociosamente cuanto ya había sido dicho: una inventio; un tratado, en particular ético y político -véase, por ejemplo, el Proemio en Monarchia de Dante Alighieri- tenía que contener, por ser tal, siempre nuevas proposiciones, es decir, hipótesis que no necesariamente se volviesen utopías, las cuales, a diferencia de las hipótesis, no están preocupadas, in primis, de su posible realización. ${ }^{5}$ En efecto, la utopía por su misma naturaleza es un sinlugar; mientras que la hipótesis siempre se relaciona con un espacio temporal. Así será en El príncipe, cuya novedad consiste en ser un tratado político; es decir, el intento de dar contenidos científicos al modo de gobernar la cosa pública. Ciencia política en el sentido recto, no sólo oblicuo, según lo afirma Aristóteles; es decir, ciencia implicante de certezas mostrativas en la materia considerada; por ejemplo, como es en nuestro caso, el del aspecto moral en el ejercicio del poder.

Afirma nuestro autor:

Desearía yo, sin embargo, que no se mirara como una reprensible presunción en un hombre de condición inferior, y baja si se quiere, el atrevimiento que él tiene de discurrir sobre los gobiernos de los príncipes y de darles reglas [...]. Si para conocer la naturaleza de los pueblos es preciso ser príncipe, para conocer la de los principados conviene estar entre el pueblo. ${ }^{6}$

Machiavelli -afirma Mauricio Ricciardi- está consciente del peligro de encontrar modalidades y órdenes nuevas, como si tuviera que encontrar aguas y tierras incógnitas, así como está

${ }^{5}$ Cfr. Platón, La República, Libro IX.

${ }^{6}$ Niccoló Machiavelli, El príncipe, 1984, México, Espasa Calpe-Mexicana, Proemio, p. 12 (desde este momento citaremos esta obra: op. cit). 
convencido de que la calidad de su discurso consiste en recurrir caminos que todavía no han sido explorados -cfr. Proemios. ${ }^{7}$

\section{La novedad de Niccoló}

¿Cuáles son los puntos más destacados que podemos señalar como portadores de una novedad en nuestro autor?

Antes que nada, la laicidad de su pensamiento político; Machiavelli con su idea de laicidad evita la división, al menos práctica, entre poder temporal y espiritual; separación que en cambio siempre habían producido las varias tendencias partidarias, las papistas y las imperiales, en las épocas anteriores y, a veces, todavía contemporáneas a nuestro autor, es decir de inmiscuir de facto sin precisas distinciones, ambos ámbitos; secularizando de esta manera el poder espiritual y clericalizando el temporal -por el momento, tomamos con grano salis esta comparación que necesitaría más profundización-; aun cuando, en el plan doctrinal, se encontraban al respecto posturas de auctoritas muy precisas, como las de Santo Tomás, entre otras. ${ }^{8}$

En este sentido, tal vez con Dante encontramos el primer intento -por cierto, precursor en casi doscientos años de las problemáticas del pensamiento moderno- por definir en un nivel más pertinente la naturaleza del poder, a saber el perteneciente a la materia temporal y a la espiritual, bajo un único principio; una díada, que salvaguarda la unidad del principio común, que rija la vida de la república y la dimensión personal insertada en la comunitaria; confiriendo al axioma del papa Gelasio y a su teoría de las dos espadas o de la metáfora del sol y de la luna,${ }^{9}$ la unidad -principio ontológico-y la utilidad -principio éticonecesarias y correspondientes para el bene esse público. ${ }^{10}$

${ }^{7}$ Mauricio Ricciardi, La República prima dello stato en il potere, 1999, Roma, G. Duso Ed. Carocci, p. 37.

${ }^{8}$ Cfr. De Regimine Principum I, 14 entre otros.

${ }^{9}$ Cfr. Gelasio a Anastasio, Ep. VIII, a. 495.

${ }^{10}$ Cfr. Monarchia, Libro III y IV. 
BRUNO GELATI

En Machiavelli estos principios y sus debidas consecuencias en el plano ético jamás resultarán en discusión. A nuestro autor le es natural la correspondencia entre la dimensión ética y la ontológica, factores que estarán como base de su realismo práctico.

Siendo mi fin escribir una cosa útil para quien la comprende, he tenido por más conducente seguir la verdad real de la materia que los desviaría de la imaginación en lo relativo a ella; porque muchos imaginaron repúblicas y principados que no se vieron ni existieron nunca. Hay tanta distancia entre saber cómo viven los hombres y saber cómo deberían vivir ellos que el quien, para gobernarlos, abandona el estudio de lo que se hace, para estudiar lo que sería más conveniente hacerse aprende más bien lo que debe obrar su ruina que lo que debe preservarle de ella. ${ }^{11}$

Por otra parte Valenti afirma que "Machiavelli, en cambio, separó la moral [en el sentido de normativas convencionales] de la política para poder mejor distinguir a la realidad, con la finalidad de intervenir mejor con medios más adecuados”. ${ }^{12}$

La realidad para nuestro autor es inexorable, se impone a las apariencias de la tentación utópica, del imaginario político; por tal motivo es el anti-utópico por antonomasia. El objeto de la naturaleza política, el bien común, se impone con todas sus implicaciones, comprendiendo in primis el entramado humano, conditio sine qua non por el conocimiento de la polis.

Que la naturaleza de los hombres sea malvagia (mala) para nuestro autor no es objeto de opinión, es certeza, un dato de la realidad del que no se puede prescindir. Y que el príncipe partiera de este dato, era parte de su oficio. Para él la virtud del ejercicio del poder cumple con su tarea practicándose, sin necesidad de sublimarse y justificarse en el

${ }^{11}$ Op. cit., cap. XV, p. 76.

${ }^{12}$ Francesco Valenti, “Niccoló L’ antiutopia”, en Revista Tracce, Milano, noviembre 1993. 
ámbito metafísico. La ética desde la época medieval era considerada la ciencia más alta de la naturaleza humana en cuanto tal; pertenecía, en efecto, al IX Cielo o sea al Cristalino, mientras que la metafísica -reproduciendo la jerarquía del saber y su correspondiente ámbito celeste, según la visión ptolemaica- concernía a los principios inmutables; pertenecía en consecuencia al Empíreo, es decir, a la ciencia divina.

Esta concepción -para nuestra mentalidad más desencantada resulta difícil de comprender-permitía simultáneamente una más amplia libertad en el campo ético y una directa referencia ontológica a la moral menos confusa que la actual, dentro de cuya concepción el mal seguía siendo mal, eminentemente imputable a la responsabilidad personal, dejando así intacta la libertad frente a la acción, cuya necesaria elección en las cuestiones particulares se confrontaba con los siguientes niveles:

a) el de la conciencia frente a la realidad, y no sólo a sí misma -o responsabilidad personal-; esta referencia finalmente se trascendía a sí misma, es decir, la última instancia de la acción se remitía a la realidad circunstancial en cuanto parte necesaria de un designio más grande;

b) el de la acción particular, comprensible con vistas a un bien, específicamente el bien público;

c) el intento de conciliar ambos aspectos: conciencia y acción es preocupación particular del príncipe, dirigida hacia la razón de Estado, máximo imperativo de conducta que remite al ámbito del ejercicio del poder.

Particularmente significativas al respecto resultan estas palabras del autor:

Se presenta en este contexto la cuestión de saber si vale más ser temido que amado. Se responde que sería menester lo uno y lo otro juntamente; pero como es difícil serlo a un mismo tiempo, el partido más seguro es ser temido, primero que amado, 
BRUNO GELATI

cuando se está en la necesidad de carecer de uno u otro ambos beneficios. $^{13}$

Que merecen el siguiente comentario de Matteucci:

El mal, para Machiavelli, permanece siendo mal; el fin siempre es un fin político, nunca ético: es la sobrevivencia del Estado, en vista del cual el hombre político, según los tiempos y las necesidades, debe proporcionar los medios.[Para concluir:] Una antropología de derivación cristiana y agustiniana está siempre presente en Machiavelli. ${ }^{14}$

\section{Las raíces del realismo del Machiavelli}

Busquemos entonces profundizar las raíces del realismo maquiaveliano.

San Agustín, en De civitate Dei, efectúa una gran síntesis del tema del poder -precisando las problemáticas que habían sido propias de los Padres de la Iglesia, en particular de Orígenes y de Eusebio de Cesárea, entre otros- cuando explica la naturaleza de las dos ciudades. Vetando toda interpretación irenista o simplemente alegórica, Agustín proyecta en el corazón del poder y de su ejercicio el conflicto real entre dos libertades: la del hombre y la de Dios, simultáneamente co-vivientes en el tiempo y en el espacio, en cuanto que esta confrontación, propiamente porque reenvía a una problemática de naturaleza metafísica, siempre necesita de un espacio de acción real; en este caso, el mundo en el sentido del campo de acción de la realidad. Al respecto, significativa es la interpretación que de esta visión nos ofrece E. Gilson en su famoso texto La metamorfosis de la ciudad de Dios. ${ }^{15}$

Precisa Ratzinger:

Para Agustín, todas las ciudades terrenas y las patrias terrenales son de segundo rango, porque él ha encontrado la ciudad de

${ }^{13}$ Op. cit., cap. XVII, p. 82.

${ }^{14}$ Cfr. N. Matteucci, A la búsqueda del orden político, 1984, Bologna, II Mulino.

${ }^{15}$ Ver a Etienne Gilson, La metamorfosis de la ciudad de Dios, 1954, Buenos Aires, Troquel. 
Dios y, en ella, la patria de todos los hombres. Nadie se llama aquí a engaño: todos los Estados de esta tierra son ciudades terrenas, aun cuando vengan gobernados por emperadores cristianos y estén más o menos poblados de ciudadanos cristianos. Son Estados de este mundo y por ello ciudades 'terrenas' y no pueden en modo alguno llegar a ser otra cosa. Como tales, constituyen formas necesarias del ordenamiento de este tiempo terrenal, y es justo preocuparse por su bien. ${ }^{16}$

De todas maneras, la contemporaneidad de las dos ciudades, como lugar de elección de pertenencia del hombre y del mismo Dios, pone en evidencia, como se mencionaba, el problema de la libertad y la abolición de la visión maniquea de la realidad, que siempre afecta a la interpretación del poder. Hay que destacar que la naturaleza del poder, cuando se vuelve maniquea, siempre corta parte de la realidad de una manera violenta, con la finalidad de dominar la que queda, sin tomar en cuenta todos los factores que en realidad la componen; el poder elimina lo que no cabe bajo su comprensión. Pero un poder adquirido de esta forma no puede gozar de una larga existencia. En cambio Machiavelli parece ser maestro en el arte de considerar a todos los factores que forman parte de una situación política, para lograr establecer el dominio equilibrado del príncipe; y en esta búsqueda consistiría también su reconocimiento a la idea de fortuna. "Los estados bien ordenados y los príncipes sabios cuidaron siempre no descontentar a los grandes [...] como también de tener contento el pueblo.”17

En este sentido, podemos mencionar brevemente su concepto de fortuna y su relación con el poder, en cuanto que aquél se emparenta con el margen imprevisible contenido en la naturaleza del poder, que habría que preservar lo más que se pueda. Vale la pena entonces precisar lo que afirma el crítico F. Valenti con respecto a la idea de fortuna, en referencia al cap. XXV de la obra, comenta:

16 J. Ratzinger, La unidad de las naciones, 1972, Madrid, Fax, p. 67-8.

${ }^{17}$ Op. cit., cap. XIX, p. 92. 
BRUNO GELATI

Machiavelli llamó ‘fortuna’ a lo que el hombre no puede preordenar; sin embargo, para él la 'fortuna' aparece sólo como una extraña necesidad extrínseca, mientras que enseguida es mucho más. Él pensó substraer espacio a lo imprevisible, si bien no lo substrajo todo, como intenta hacer de una forma poco diestra toda teoría utópica.

Esta disminución de la importancia [de lo imprevisible], tal vez le impidió ver, en consecuencia, que las fuerzas que mueven a la historia son las mismas que se agitan en el corazón del hombre. $^{18}$

Retomado el concepto de libertad mencionado en La ciudad de Dios, es preciso añadir que el movimiento que se engendra de ella no puede ser colocado a un nivel ideal, sino que acontece en el plan real, en el que el bien y el mal no se dan en una relación de exclusión, ni dialéctica, como a veces se pudiera entender, sino que se encuentran interrelacionados de una manera que permite la elección de uno o del otro, ordenada a una finalidad que se introduce como criterio de valoración antes de la decisión misma del acto moral particular. Por eso, pertenecer a una de las dos ciudades nunca es un acto definitivo y permanente de la voluntad del hombre, sino un constante itinerario en orden a la realidad que, limitando por su circunstancialidad, al mismo tiempo posibilita la elección del acto moral particular. Dentro de esta concepción, entonces, se abre necesariamente un campo de acción que se dirige más al acto real que a la intención, que juzga lo que acaece en orden a sus consecuencias, y reconoce la subsistencia de realidades heterogéneas y plurales que, en caso contrario no podrían existir, eliminando la concepción La ciudad de Dios como campo de acción de la libertad misma, como puede observarse:

Cuando sucede que una persona hizo, en el orden civil, una acción nada común, tanto en bien como en mal, es menester

${ }^{18}$ Francesco Valenti, “Niccoló L’ antiutopia”, en Revista Tracce, Milano, noviembre 1993. 
hallar, para premiarla o castigarla, un modo notable que al público dé amplia materia de hablar. En una palabra: el príncipe debe, ante todo, ingeniarse para que cada una de sus operaciones se dirija a proporcionarle fama de gran hombre y de príncipe de un superior genio. ${ }^{19}$

\section{Societas medievalis}

La postura de La ciudad de Dios atraviesa a la Edad Media, aun cuando con la afirmación en la sociedad de la realidad feudal, la civitas cristiana ha tenido que confrontarse con interpretaciones hegemónicas del momento histórico que la contuvo y determinó. Bastaría pensar en la gran construcción del pensamiento de Escoto Erígena que sostuvo la idea feudal hasta su decadencia; ${ }^{20}$ en particular, la identificación natural-ontológica entre sociedad y poder cívico divinizado, construcción que farisaicamente podría escandalizar a los cultores de los sistemas políticos modernos; en realidad sería suficiente remitirnos a la raíz del pensamiento del estado religioso, de memoria hegeliana, cuyas ramificaciones rigen el sistema mundial contemporáneo, para volvernos más críticos en relación a nuestra supuesta idea de progreso. Sin embargo reconozcamos que no es fácil pensar, para nosotros los contemporáneos, en una sociedad como la feudal, en la cual el ámbito eclesiástico ejercía el poder temporal al igual que el laical; sobre todo cuando la societas de la Iglesia, principalmente en el Occidente Cristiano, ha actuado más según una naturaleza sui generis y entonces de una forma más laica que integrista en el mundo: mirar a lo religioso como un aspecto relacionado intrínsecamente con el cívico, aunque no idéntico. Motivo éste por el cual encontramos en el siglo XIII una de las más altas expresiones de la libertad asociativa y política, no sólo de la Edad Media, sino también de las épocas sucesivas, a saber

${ }^{19}$ Op. cit., cap. XXI, p. 110.

${ }^{20} \mathrm{Cfr}$. De divisione naturae. 
la comuna y en particular el nacimiento de las cofradías, donde el aspecto laico asumía, en su estructura constitutiva, el factor religioso volviendo, de esta forma, floreciente la cultura en la unidad de ambas expresiones. $^{21}$

A Machiavelli, por ejemplo, le parece natural que la misma realidad eclesiástica pudiese defender sus dominios territoriales al igual que los demás principados. Nunca maravilló a nuestro autor que un Julio II o un Alejandro VI defendieran en primera persona sus ciudades y que, inclusive, se hicieran promotores de guerras facciosas. En efecto, no estaba en discusión esta legitimidad, hasta tomar como emblemáticos los grandes jueces de la historia sagrada, como más de una vez ocurre con nuestro autor; por ejemplo cuando señala: “...Moisés, Ciro, Teseo y Rómulo no habrían podido observar por mucho tiempo sus constituciones si hubieran estado dispersos, como le sucedió al fraile Jerónimo Savonarola."22 O bien pasando enseguida a la alabanza de Moisés cuando dice:

Estos Estados [los eclesiásticos]... son los únicos que prosperan y están seguros. Pero como son gobernados por causas superiores, a los cuales la razón humana no alcanza, los pasaré en silencio; sería menester presuntuoso y temerario siendo discurrir sobre sus sobranías, elegidos y conservados por Dios mismo.

[...] Julio II no solamente signó el curso observado por este Alejandro [VI], sino que también forma el designo de con-

${ }^{21}$ Sui generis, en el sentido que traspasa todo género de definición sociopolítica, pero que está en ella. En particular, deberíamos remitirnos a la Carta a Diogneto del II siglo d.C., en donde se afirma: ...porque ello [los cristianos] habitan patrias que les son propias, pero como extranjeros estarán en ellas domiciliados; en todo participan como ciudadanos y se mantienen aparte de todo como extranjeros; toda patria extraña es su patria y toda patria les es extraña. No son apátridas.

${ }^{22}$ Op. cit., cap. VI, p. 31. 
quistar a Bolonia, reducir a los venecianos, arrojar de Italia a los franceses. ${ }^{23}$

Cuando Niccoló escribe piensa sobre todo en la nación itálica y tiene conciencia de que la época feudal no tuvo fortuna en este suelo. En efecto, después de la muerte de Ludovico el Pío (840) lo que tenía que constituir en gran parte el reino Lotaringio, se irá disgregando en varios dominios. Significativo es el hecho de que ya alrededor del siglo XI en Italia el sistema feudal empieza políticamente a tambalear, cuando el sur de Roma, bajo la influencia del papado, en particular la Trinacría, se disputaba entre longobardos, griegos, árabes, normandos, aragoneses, angevinos y germánicos, entre otros. Mientras en el Centro y en el Norte de la península -con excepción del patrimonio petrino que había llegado a disputarse con los venecianos el dominio inferior del Po (Ferrara) y la Romaña, todavía en el tiempo de Machiavelli- ya con Matilde de Canosa (1076) y sobre todo Toscana, Emilia y Lombardía se habían puesto las bases para una de las expresiones más significativas de la libertad popular, como fueron las comunas; considerando además que los dominios del papado nunca estuvieron propiamente bajo un sistema feudal. Bastaría recordar que Bolonia gozaba ya desde el siglo XII de un gobierno formado por las familias notables de la ciudad que incluía también territorio que se extendía fuera del área urbana; la misma Universidad gozaba ya desde el siglo XII de su completa autonomía reconocida por el Papado y por el Imperio.

En efecto, la lucha para las investiduras había permitido huir del esquema piramidal feudal, hasta volcar su vértice. Distintas, como sabemos, fueron las dinámicas que caracterizaron los procesos nacionales en Francia, Inglaterra e incluso la misma Alemania.

Mencionamos todo esto para remitirnos más propiamente a los orígenes de la época de nuestro autor, cuando, desde el siglo de oro de la Edad Media, el XIII ya se había impuesto, el proceso de una cierta plutocracia; situación que encontramos ampliamente descrita en sus

${ }^{23}$ Op. cit., cap. XI, p. 60. 
BRUNO GELATI

mismas obras. Es decir, la situación tenía sus raíces en el desarrollo económico de la Edad Media y no en el Cinquecento, como pretendió Max Weber, quien hace remontar el nacimiento del capitalismo contemporáneo a esta época, tesis que se desmiente en dos direcciones. Primero, en cuanto que lo que actualmente nuestro sistema capitalista realiza no es sólo una expropiación del producto del trabajo, sino del sentido del trabajo mismo, es decir produce una alteración en la dinámica ontológica entre el trabajo y el sujeto, o sea en la relación entre el ser del hombre y su expresión creativa original, lo cual no sucedía en la época renacentista. Como afirma O. Nuccio:

Weber hipotetiza un ‘ideal-typo' [...] para idealizar un 'homo oeconomicus’ abstrayéndolo de la complejidad de las muchas facetas del humano, [mientras que, para Macchiavelli,] lo que caracteriza el espíritu capitalista es la racionalidad del comportamiento [orientado] al provecho y adecúa los medios a los fines, y esto es el comportamiento del italiano de $1200 .^{24}$

Además, esta visión de la autonomía política y de la realidad productiva racional de la polis -y esto sería el segundo aspecto- formaban el entramado sociocultural en el cual el pensamiento de nuestro autor se desarrolla; precisamente una visión racional en la que las virtudes intelectuales, primera entre todas la prudencia, campean: "este italiano, quien racionaliza el comportamiento económico, es un hombre que asiste a la Misa”. 25

\section{Laicidad e historia en Machiavelli}

Para caracterizar el pensamiento de nuestro autor, en este contexto político cultural es de interés destacar los conceptos de laicidad y de historia.

${ }^{24}$ O. Nuccio, en Revista Tracce, marzo 1994, p. 15-6.

${ }^{25}$ Idem. 


\subsection{Laicidad}

En primer lugar hay que considerar que el poder en la época medieval y todavía en la de nuestro autor, es fundamentalmente laico, no idealista como sucederá después. Las ideas renacentistas de procedencia neo-platónica no tendrán un peso considerable en él. En aquella época la cultura era típicamente laica y en particular la florentina, en cuanto que la experiencia religiosa se constituía en societas -según hemos mencionado- sin separación entre las esferas: laica y la religiosa; aspectos que se habían definido no sólo bajo un perfil teórico -según las ideas de Roger Bacon, Dante, Tomás de Aquino, Juan de París, Marsilio de Padua, etcétera-sino más bien como experiencia, en particular en la participación en un proyecto común de sociedad: la construcción de una realidad civil que para nuestro autor se identificará con el Estado; en la que la razón de Estado pudiera amparar las deficiencias estructurales de la misma naturaleza humana, como puede apreciarse en estos fragmentos:

...Conviene observar que el natural de los pueblos es variable. Se podrá hacerles creer fácilmente una cosa; pero habrá dificultad para hacerlos persistir en esta creencia. En consecuencia de lo cual es menester constituirse de modo que, cuando hayan cesado de creer, sea posible hacerlos creer todavía.

O también:

El que se hace señor de una ciudad acostumbrada a vivir libre y no descompone su régimen, debe contar con ser liberado él mismo por ella. ${ }^{26}[\ldots]$

Sin embargo, los espartanos, que habían tenido Atenas y Tebas por medio de un consejo de un costo mínimo de ciudadanos, acabaron perdiéndolo. ${ }^{27}$

${ }^{26}$ Op. cit., cap. V, p. 29.

27 Ibid. 
Esta problemática va más allá del aspecto siempre ambiguo y distrayente medio-fin, a la que ha sido reducida la temática de Machiavelli por parte de muchos críticos. Al respecto hay que destacar que para nuestro autor la christianitas no se limitaba a una vaga religiosidad, sino que se precisaba en un modo de estar en el mundo; en particular ella entraba en la misma idea de Estado. Si el bien de toda la sociedad está en el Estado -interesante sería también hacer un análisis filológico de la aplicación de este término al principado, que re-envía al modo participativo de estar en la realidad- el deber moral del príncipe consistiría en mantener su forma de ser o su estar, o sea su Estado, incluyendo la societas cristiana.

Por cierto que en esta definición el concepto de nación -realidad culturalmente más amplia y menos definida en su entorno geográficoparecería estar al margen del pensamiento de nuestro autor, aunque no esté excluida -según veremos más adelante-; más bien, el Estado es entendido como ámbito en el cual el poder encuentra una modalidad práctica y no absoluta en sus principios, a los efectos de mantener la cosa pública según la finalidad que le corresponde; primera entre todo el orden social.

Lo peor que el príncipe tiene que temer de un pueblo que no le ama, es el ser abandonado por él, pero si le son contrarios los grandes, no solamente debe temer ser abandonado, sino también atacado y destruido por ellos. ${ }^{28}$

[además:]

Cualquiera que haya fortificado bien el lugar de su mansión y se haya portado bien con sus gobernadores [...] no será atacado sino con mucha circunspección, porque los hombres siempre miran con tibieza las empresas que les presentan dificultades. ${ }^{29}$

${ }^{28}$ Op. cit., cap. IX, p. 53.

${ }^{29}$ Op. cit., cap. X, p. 56. 


\subsection{La historia}

El segundo aspecto a considerar es la visión realista que Machiavelli tiene de la historia. La historiografía de su amigo Guicciardini no le interesa mucho, en cuanto que éste, según él, por más que se esfuerce por hacer historia, no supera el particularismo.

La historia para nuestro autor es actuación hic et nunc o no es; no tiene valor para él el recuerdo por el recuerdo; la demagogia, en la que mucho remembrar humanístico había caído no cumplía con sus expectativas. La gloria de la República o de los errores de Roma, no tienen importancia si no llegan a ser objeto de una hermenéutica repropositiva del factum presente. No le interesan las gestas gloriosas del pasado sino lo que ellas sugieren en el presente. En este punto nuestro autor se encuentra más cercano al realismo histórico de Dante, si bien éste nunca renuncia a tener una visión escatológica del sentido de la historia, mientras que el secretario florentino se limita a un aspecto más inmediato.

Convenía que Rómulo a su nacimiento no quedara en Alba y fuera expuesto, para que se hiciera rey de Roma y fundador de un Estado que formó la patria suya. ${ }^{30}$

El príncipe, para ejercitar su espíritu, debe leer las historias; y al contemplar las acciones de los varones insignes, debe notar particularmente cómo se condujeron ellos en las guerras, examinar las causas de sus victorias, a fin de conseguirlas él mismo. $^{31}$

Diríamos entonces que la historia vale como presencia práctica. ¿En qué sentido?

${ }^{30}$ Op. cit., cap. VI, p. 32.

${ }^{31}$ Op. cit., cap. XIV, p. 73. 
BRUNO GELATI

5.2.1 Primero, en el sentido de que más que el intento de reproducir una historia de Roma o de Grecia, a nuestro autor le interesa el factum, no propiamente en el sentido viquiano, sino como algo incluso episódico, pero libre del entorno rapsódico o didascálico en el que el historiador siempre procura envolver a la historia. Y tampoco el factum como repetitiva circunstancia, según la visión idealista; sino el hecho despojado de una preocupación eminentemente propedéutica; es decir, el factum histórico vale por sí mismo, por lo que el acto es como lo simplemente acaecido y presentado como tal hecho.

Esta especie de fenomenología de la historia no necesita de una epoqué, porque en esta hermenéutica ningún análisis particular, ni suspensión sería necesaria para constituir el juicio, sino que si el acto acaece, simplemente vale; permanece como memoria más que como recuerdo; o mejor dicho, se vuelve presente en cuanto que si ha acaecido permanece definitivamente.

5.2.2 Segundo: el factum en su valor moral -y no sólo ontológico, como en el primer aspecto se ha descrito- por el hecho de existir, constituye también un referente justificativo. Se trata en efecto del aspecto ético de la historia; si el factum es acaecimiento, es real, entonces más que preocuparse por su verdad y eticidad, su comprensión se sitúa en el hecho positivo acontecido y, en consecuencia, se justifica positiva o negativamente como acto moral útil para el bien público, porque ha sucedido, finalmente, con relacion al bene esse.

5.2.3 Tercero: la relación entre la naturaleza de lo acaecido y la dimensión antropológica se da sólo en el presente, en cuanto que es el hombre en su actuar el que permite a la dimensión histórica su valor actual; sin que se pretenda tener de ésta una dimensión permanente o de un futuro cerrado. En efecto, siguiendo a nuestro pensador, es la dimensión contemporánea la que permite al hombre mantener la historia en su conciencia, sin que en esta actualidad se pretenda encontrar una justificación. No hay que olvidar que Machiavelli, más que filósofo, en el sentido contemplativo, es un pensador que con base en su 
experiencia busca establecer criterios objetivos y justificativos en el campo moral para la política, o sea para la re-publica. En este sentido no es que disminuya el valor de la historicidad, sino que privilegia la dimensión experiencial a su interpretación; es decir, lo que el factum sugiere al actuar consciente del hombre que enfrenta su presente.

En este punto se intuye algo más de la afirmación tout-court: historia magistra vitae; para nuestro autor, más que maestra de vida, la historia vale si se impone el factum; si es emblemática más que propedéutica o didáctica, o más aún metafórica o alegórica.

Al respecto afirma $M$. D’Addio:

El pensamiento político de Machiavelli brota de la sufrida experiencia de la profunda crisis religiosa, civil y política italiana del Cinquecento: su realismo político está también conectado con la amarga constatación de una radical corrupción de los órdenes civil y político italianos. Los asuntos políticos de Florencia asumen un valor emblemático e invisten no sólo la situación política italiana, sino que se refieren, en última instancia, al problema mismo de la política; es decir, a la manera con la que es posible rescatar al hombre de su co-natural contradicción, de su no-contentabilidad, de su cerrado y enseguida feroz egoísmo; y, entonces, de su tendencial vocación a la mutación continua, es decir al desorden: se trata, entonces, de llevar al hombre hacia el orden, de educarlo al respecto en las leyes y las instituciones.

Esta voluntad de orden coincidirá con el Estado: ‘dominación firme sobre los pueblos'. ${ }^{32}$

[...] El estado, en conclusión, es el constante empeño, para la continua vigilancia con relación al inextirpable male oscuro de las leyes y de las instituciones. [...] Por ende, Machiavelli es un escritor político inquietante, seguramente incómodo, para no decir inactual. ${ }^{33}$

${ }^{32}$ Mario D’ Addio, “L’ Inattuale”, en revista Tracce, diciembre 1993, p. 46. ${ }^{33}$ Idem. 
BRUNO GELATI

\section{Historia y realidad}

En este punto de nuestra reflexión se vuelve lícita una pregunta: ¿qué relación hay para nuestro autor entre historia y realidad? Ya hemos precisado tres aspectos sustanciales al respecto (ontológico, ético y antropológico), pero todo esto no bastaría sin precisar que el punctum dolens del pensamiento actual, el que constituye en cambio la originalidad de nuestro pensador, consistente en la huida de la problemática de carácter onto-teológico -si bien ésta puede ser fundamental para entender el problema meta-ético, a saber el concepto de diferencia ontológica entre el ser y el esente o ir siendo- y sus consecuencias en el aspecto real; para, en cambio, subrayar más que la idea de diferencia, la de desproporción en la participación del ser, en particular en el ser del hombre.

En efecto, la idea de diferencia, tan cara a muchos de los ontólogos contemporáneos, muy en seguida desemboca en una visión utópica y no real de la existencia; es decir, se queda a nivel idealista, en cuanto que el concepto de diferencia de la existencia nunca llega a ser realmente comprendido por la naturaleza del ser humano. Existe una diferencia ontológica que induce, en el plano ético, la idea de la imposible realización de algo realizable. En virtud de este padecimiento, el hombre tendería a inclinarse hacia a la utopía que, en el caso de su aplicación -véase la experiencia de Savonarola en los tiempos de nuestro autorparadójicamente siempre desencadena violencia vana, inútil e irracional en cuanto que pretendería, como contrapunto, eliminar finalmente esta inevitable diferencia. Para Machiavelli el problema es distinto, la realidad humana es lo que es y es siempre desproporcionada con respecto a lo que ella re-envía o sub-entiende. Motivo por el cual la ética, que es la formalitas explicativa del acto humano, también es siempre inadecuada en su aplicación, en cuanto que punta al actuar presente en vista de lo que la constituye como perfecta, y entonces como tensión.

La desproporción entre el ser y la realidad particular permite entender entonces las raíces del realismo maquiaveliano, sin por eso caer en un 
pesimismo ontológico, pues lo desproporcionado permite la búsqueda de la virtud, es decir, de la justa proporción. Mientras que la idea de diferencia distancia y priva a la conciencia de una real tensión moral, la desproporción, aunque no elimine la diferencia ontológica, vuelve posible la relación con la realidad perfectible y no perfecta.

Precisamente por la idea de desproporción, El príncipe inaugura una verdadera ciencia política, en cuanto que sin pretender explicar los últimos principios filosóficos, logra dar al aspecto político un carácter específico y por ende universal. Esto porque lo universal es el carácter mismo de la naturaleza que se particulariza, siempre cuando lo específico intencionalmente no excluya, desde su punto de partida, la relación con todos los factores de la realidad que, siendo más amplios de lo específico, siempre tienen un nexo con el particular a tal grado que éste, en cierto sentido, contiene el universal, tiende hacia él, en caso contrario se caería en la ideología.

Y precisamente porque estas proporciones son aplicables de lo particular a lo general, en nuestro autor más que de filosofía stricto sensu podemos hablar de ciencia, como afirma Paolo Caserta:

Cuando en 1498 Machiavelli es nombrado Secretario de la Cancelería florentina, no es exactamente un 'pionero de la modernidad’, según definieron De Sanctis o el Carducci; su cultura y su mentalidad están bien arraigadas en el Medioevo, al igual que las de Florencia, ciudad en la que, a diferencia de otros centros italianos, la influencia de la cultura medieval se encuentra mucho más extendida, por lo que los conceptos y los ideales que Machiavelli expresa no son nuevos, sino que se insertan en el cotidiano debate político florentino.

Además, es reductivo decir que él afirma ideales terrenales y laicos en contra de prejuicios eclesiásticos y metafísicos. ¿Por qué impacta tanto, entonces, Machiavelli? Sin duda, por su singular capacidad de leer y descifrar el comportamiento político de quien lo rodea, la atención con la que se sitúa en la 
BRUNO GELATI

realidad, a partir de la conciencia de la natural predisposición de la naturaleza humana.

[...] Las modalidades de las acciones indicadas por Machiavelli, seguramente no tenían nada de blasfemo para sus contemporáneos inmersos en esa realidad política, como el Cardenal Giovanni, futuro Papa León X o Benedicto VII, quien le comisionará las Istorie. ${ }^{34}$

\section{La unidad de la cultura}

Para cerrar esta exposición recordemos la pregunta abierta en nuestro inicio: ¿De dónde le viene, a Machiavelli, la argucia y la pasión por la res publica? Si bien en el Proemio de El príncipe se encuentra una justificación de todo el tratado, la intencion que lo ha determinado a escribir ésta, su obra maestra, sólo aparece al final, cuando exalta su profundo sentimiento de amor patrio en la Exhortación a liberar Italia de los nuevos bárbaros. Se trata del mismo amor que más allá de la condición particular, crea en el hombre un vínculo de profunda unidad con su propia tradición, con su ethos. Con Dante y Petrarca, Machiavelli se une al coro de quienes han dado forma a la realidad cultural de un pueblo, más allá de sus confines geográficos; es decir, que han abierto las conciencias hacia una pertenencia de unidad, de lengua, de religión y de tradiciones -no en el sentido homogéneo, en cuanto que esto no correspondería a la realidad, sino más precisamente a una ecumene-: la conciencia de pertenencia a un lugar en el cual, por ejemplo en este caso particular Roma, y sobre todo la Roma de la República, de las libertades sociales y políticas, de la catolicidad y de los Césares, y también con la Roma en donde Cristo es romano (como diría Dante). Un ethos donde la idea de Estado se articule más allá de una lógica idealista-nacionalista: una idea de nación que permitirá durante siglos ser terreno fértil para un ecumenismo en donde la unidad política se

${ }^{34}$ Paolo Caserta, “Fuggir l’ Inferno”, Tracce, Milán, noviembre 1993. 
ha impuesto como identificación entre estado y nación. Para el espíritu de nuestro autor, la razón de Estado no elimina sino que reconoce la raíz de las múltiples formas culturales que componen una realidad nacional.

Para concluir estos pensamientos bastaría hacer mención de los dos emblemáticos autores arriba citados pues la simple repetición de los versos de los dos grandes padres de la italianidad, no sólo provocan una profunda emoción sino que nos persuaden de que están animados por los mismos anhelos de unidad cultural que la Exhortación final de El príncipe.

Dante así describe el encuentro entre Virgilio y su paisano Sordelo: (...) “O Mantovano, io son Sordello/della tua terra” el' un l' alto abbracciava.

Ahí serva Italia, di dolore ostello,/ nave sanza nocchiere in gran tempesta,/Non donna di provincie, ma bordello/Quell' anima gentil fu cosí presta,/Sol por lo dolce suon della sua terra,/Di farse al cittadin suo quivi festa;/ e ora in te non stanno sanza guerra/li vivi tuoi, e l'un l'altro si rode/ di quei ch'un muro ed una fossa serra.

(..."Oh mantuano, soy Sordelo, de tu tierra”, y uno a otro se abrazaba. ¡Ay, sierva Italia, asilo eres de duelo, y, en la tormenta, nave sin barquero, y burdel, más no reina de más suelo! Aquel gentil mostrase tan ligero, Sólo por el son dulce de su tierra, Al ser con el paisano lisonjero; Y tus vivos, en ti, no están sin guerra, $\mathrm{Y}$ el uno al otro roe y acribilla, De los que una muralla y foso encierra.) ${ }^{35}$

Petrarca se une al Divino poeta:

Italia mía, bene che'l parlar sia indarno/ a le piaghe mortali che nel bel corpo tuo sí spesse veggio,/Piacermi almen che' miei sospir sian quali/Spera 'I Tevero e l'Arno,/E 'l Po, dove doglioso e grave or seggio.[...]

Voi, cui fortuna ha posto in mano il freno/ de le belle contrade,/ di che nulla pietá par che vi stringa,/ che fan qui tante pellegrine spade/? Perché 'I verde terreno/Del barbanico sangue si dipinga?

${ }^{35}$ Dante Alighieri, Purgatorio, Canto VI v. 74-84. 


\section{BRUNO GELATI}

(Italia mía, aunque hablar no sirva para sanar tus plagas mortales que en tu cuerpo yo veo sí numerosas, me consuela, al menos, que mis versos sean como los esperas los ríos Tiber, el Arno y el Po, donde dolorido y pesado estoy sentado. [...]

Ustedes, a quienes la fortuna puso en las manos las riendas de los bellos contradas, las cuales parece que no les cause piedad ¿qué hacen aquí tantas espadas forasteras para que el terreno verde se pinte de la sangre de los bárbaros?). ${ }^{36}$

${ }^{36}$ Francesco Petrarca, C. XXVIII, Italia mía, v. 16 y 1722. 